\title{
Thermodynamic Study of Copper Sulphate and Zinc Sulphate in Water and Binary Aqueous Mixtures of Propylene Glycol
}

\author{
R.C.THAKUR*, RAVI SHARMA, MEENAKSHI and ASHISH KUMAR \\ Department of Chemistry, School of Physical Sciences, \\ Lovely Professional University, Phagwara, Punjab, India. \\ *Corresponding author Email: rameshchandthakur@yahoo.co.in
}

http://dx.doi.org/10.13005/ojc/310143

(Received: December 01, 2014; Accepted: January 10, 2015)

\begin{abstract}
Partial molar volumes of copper sulphate and zinc sulphate have been determined in water and binary aqueous mixtures of propylene glycol $(2,4,6$ and $8 \%$ by weight of propylene glycol) at $303.15 \mathrm{~K}$ with the help of density measurements. Effect of temperature on the partial molar volumes was also analysed for these salts in water and binary aqueous mixtures of propylene glycol. Results obtained have been analysed by Masson's equation and the experimental values of slopes and partial molar volumes of these transition metals sulphates have been interpreted in terms of ion-ion or ion -solvent interactions. Limiting molar expansibilities $\left(\Phi_{E}^{0}\right)$ have also been determined which are interpreted in terms of structure making or breaking capacities of transition metal sulphates. The transition metal sulphates have been found as structure promoter in water and binary aqueous mixture of propylene glycol.
\end{abstract}

Key words: Partial molar volumes, structure maker, transition metal sulphates.

\section{INTRODUCTION}

In thermodynamic properties, partial molar volume is one of the most important tool which is useful in elucidating the various types of interactions like ion-ion, ion - solvent and solvent solvent interactions occurring in aqueous as well as non-aqueous solutions ${ }^{1-10}$. The structure and properties of the solutions can be determined by these interactions and appreciable work has been done for various electrolytes in different binary aqueous mixtures but less work is done forcopper sulphate and zinc sulphate in binary aqueous mixtures of propylene glycol. So, the present study is to understand the interactions of copper sulphate and zinc sulphate in water and propylene glycol + water system. 3d transition metal ions play an important role in different life systems as these are 
present in different minerals, vitamins, enzymes and proteins. Copper sulphate is very important transition metal salt in agriculture, public health, decorative trades, mining, paint, petroleum and textile industries. On the other hand zinc sulphate is an important mineral. It is an herbicide typically used for moss control. Zinc can be found naturally in the environment, foods and water. Due to the importance in geology, industrial and biological systems, a need has developed for accurate thermodynamic data for transition metal salts in aqueous solutions. Propylene glycol is a commonly used drug solubilizer in topical, oral and injectable medications. It is used as stabilizer for vitamins and as a water-miscible co-solvent. Propylene glycol has been used for over 50 years in a large variety of industrial applications.

\section{EXPERIMENTAL}

The reagents, copper sulphate [CuSO $4.7 \mathrm{H}_{2} \mathrm{O}, \mathrm{M}$. W. $249.68 \mathrm{~g}$ ], zinc sulphate $\left[\mathrm{ZnSO}_{4} .7 \mathrm{H}_{2} \mathrm{O}, \mathrm{M} . \mathrm{W} .287 .54 \mathrm{~g}\right]$ and propylene glycol $\left[\mathrm{CH}_{3} \mathrm{CH}(\mathrm{OH}), \mathrm{CH}_{2} \mathrm{OH}\right.$ M. W. $\left.76.10 \mathrm{~g}\right]$ were taken of AR grade. All these reagents were used after drying over $\mathrm{P}_{2} \mathrm{O}_{5}$ in desiccators. Fresh triple distilled water was used as standard solvent for preparing binary aqueous mixtures of propylene glycol and other solutions.

The binary aqueous mixtures of propylene glycol and five different concentrations of above mentioned transition metal sulphates were prepared by weight and the conversion of molality $(\mathrm{m})$ into molar concentration $(\mathrm{C})$ was done by using the standard expression ${ }^{11}$ :

$$
C=\frac{m d 1000}{1000+m M_{2}}
$$

Where, $d$ is the density of solution and $M_{2}$ is the molecular weight of transition metal sulphate salts.

The density was measured with the help of an apparatus similar to the one reported by Ward and Millero' ${ }^{12}$. This apparatus consist of a glass float which is suspended with nylon thread from a balance pan into a cylindrical sample container. The sample container has a bakelite top and placed in a water bath. The whole assembly of sample container and water-bath was placed in thermostat whose temperature was controlled with the help of an electronic relay. The fluctuation in temperature was within $\pm 0.01 \mathrm{~K}$. The densities of different aqueous solution of transition metal sulphates were calculated with the help of the equation:

$$
d-d_{0}=\frac{\left(W_{0}-W\right)}{V_{f}}
$$

Here, $d$ and $d_{0}$ are the densities of sample solution and of water respectively; $w$ and $w_{0}$ are the weights of float in sample solution and water respectively.The calibration of float was checkedby measuring density of pure methanol at $308.15 \mathrm{~K}$ (our value $d=0.7773 \mathrm{gcm}^{-3}$ is in good agreement with literature valued $\left.=0.7770 \mathrm{gcm}^{-3}\right)^{13}$. The accuracy in the density measurements was $1 \times 10^{-4} \mathrm{gcm}^{-3}$.

The apparent molar volumes $\left(\phi_{\mathrm{v}}\right)$ were calculated from the density data using the following expression $^{14}$

$$
\Phi_{v}=\frac{1000\left(d_{0}-d\right)}{c d_{0}}+\frac{M_{2}}{d_{0}}
$$

where $d_{0}$ is the density of propylene glycol +water as solvent and $d$ is the density of solution; $c$ is the molar concentration of sulphate salts and $\mathrm{M}_{2}$ is the molecular weight of transition metal sulphates. The density measurements were carried out in a well stirred water bath with a temperature control of $\pm 0.01 \mathrm{~K}$

\section{RESULTS AND DISCUSSION}

The densities of aqueous solutions of copper sulphate and zinc sulphate in different compositions of propylene glycol + water $(2,4,6$ and $8 \%)$ at $303.15 \mathrm{~K}$ have been measured and were used to calculate the apparent molar volumes $\phi_{v}$. The plot of $\phi_{v}$ verses $\sqrt{ } \mathrm{C}$ were found to be linear in different compositions of propylene glycol + water. A sample plot for copper sulphate in different compositions of propylene glycol +water at $308.15 \mathrm{~K}$ is shown in fig. 1 . The partial molar volumes $\phi_{v}{ }^{0}$ were 
calculated by using least square fit to the linear plots of experimental values of $\phi_{v}{ }^{0}$ versus square root of molar concentration $c$ and using Masson equation

$$
\phi_{v}=\phi_{v}^{0}+S_{v}^{*} \mathrm{C}^{1 / 2}
$$

where $\Phi^{\circ}-\Delta \bar{V}^{0}$ is the partial molar volume and is the experimental slope.
Table 1 shows the values of $\phi_{v}{ }^{0}$ and $S^{*}$, calculated in different compositions of binary aqueous mixture of propylene glycol at $308.15 \mathrm{~K}$. It is clear, from table 1 , that the values of slopes $\left(\mathrm{S}^{*}{ }_{\mathrm{v}}\right)$ are positive in water as well as in propylene glycol+ water mixture at $308.15 \mathrm{~K}$ in all the compositions for the transition metal sulphates. The positive values of $S^{*}{ }_{v}$ for both the transition metal sulphates, indicate the presence of strong ion- ion interactions. Also, from Table 1, it is clear that the magnitude of $\phi_{v}{ }^{0}$ values of these transition metal sulphates increases

Table 1: Partial molar volumes $\phi_{v}^{0}$, experimental slopes $S^{*}$ and partial molar volumes of transfer $\Delta \overline{\mathrm{V}}_{(\mathrm{tr})}^{0}$ for copper sulphate and zinc sulphate in water and

propylene glycol + water mixtures at $308.15 \mathrm{~K}$

\begin{tabular}{|c|c|c|c|c|c|c|}
\hline \multirow{2}{*}{$\begin{array}{l}\text { propylene glycol } \\
+ \text { water (\% w/w ) }\end{array}$} & \multicolumn{3}{|c|}{ Copper Sulphate } & \multicolumn{3}{|c|}{ Zinc Sulphate } \\
\hline & $\begin{array}{c}\phi_{\mathrm{v}}^{0}\left(\mathrm{~cm}^{3}\right. \\
\left.\mathrm{mol}^{-1}\right)\end{array}$ & $\begin{array}{c}\mathrm{S}^{*}{ }_{v} \\
\left(\mathrm{~cm}^{3} \mathrm{dm}^{3 / 2}\right. \\
\left.\mathrm{mol}^{-3 / 2}\right)\end{array}$ & $\begin{array}{c}\Delta \overline{\mathrm{V}}_{(\mathrm{tr})}^{0} \\
\left(\mathrm{~cm}^{3} \mathrm{~mol}^{-1}\right)\end{array}$ & $\begin{array}{c}\phi_{v}^{0}\left(\mathbf{c m}^{3}\right. \\
\left.\mathrm{mol}^{-1}\right)\end{array}$ & $\begin{array}{c}\mathrm{S}^{*}{ }_{v} \\
\left(\mathrm{~cm}^{3} \mathrm{dm}^{3 / 2}\right. \\
\left.\mathrm{mol}^{-3 / 2}\right)\end{array}$ & $\begin{array}{c}\Delta \overline{\mathrm{V}}_{(\mathrm{tr})}^{0} \\
\left(\mathrm{~cm}^{3} \mathrm{~mol}^{-1}\right)\end{array}$ \\
\hline 0 (Water) & 58.42 & 9.66 & - & 103.40 & 6.21 & . \\
\hline 2 & 144.20 & 6.26 & 85.78 & 130.30 & 6.20 & 26.90 \\
\hline 4 & 139.10 & 6.28 & 80.68 & 120.40 & 6.70 & 17.00 \\
\hline 6 & 121.70 & 6.37 & 63.28 & 119.10 & 7.56 & 15.70 \\
\hline 8 & 114.80 & 6.39 & 56.38 & 117.40 & 7.64 & 14.00 \\
\hline
\end{tabular}

Table 2: Partial molar volumes $\phi_{v}^{0}$ and experimental slopes $S^{*}$ for copper sulphate and zinc sulphate in water and $2 \%(w / w)$ propylene glycol + water mixture at different temperatures

\begin{tabular}{|c|c|c|c|c|}
\hline \multirow{2}{*}{$\begin{array}{l}\text { Temperature } \\
\text { (K) }\end{array}$} & \multicolumn{2}{|c|}{ Copper Sulphate (in water) } & \multicolumn{2}{|c|}{ Zinc Sulphate(in water) } \\
\hline & $\begin{array}{c}\phi_{v}^{0} \\
\left(\mathrm{~cm}^{3} \mathrm{~mol}^{-1}\right)\end{array}$ & $\begin{array}{c}\mathrm{S}^{*}{ }_{v} \\
\left(\mathrm{~cm}^{3} \mathrm{dm}^{3 / 2} \mathrm{~mol}^{-3 / 2}\right)\end{array}$ & $\begin{array}{c}\phi^{0}{ }_{v} \\
\left(\mathrm{~cm}^{3} \mathrm{~mol}^{-1}\right)\end{array}$ & $\begin{array}{c}\mathrm{S}^{*}{ }_{v} \\
\left(\mathrm{~cm}^{3} \mathrm{dm}^{3 / 2} \mathrm{~mol}^{-3 / 2}\right)\end{array}$ \\
\hline 303.15 & 72.28 & 9.56 & 104.9 & 6.15 \\
\hline 308.15 & 58.42 & 9.66 & 103.4 & 6.21 \\
\hline 313.15 & 41.12 & 9.70 & 97.72 & 6.29 \\
\hline 318.15 & 41.10 & 11.57 & 87.32 & 6.37 \\
\hline \multirow[t]{2}{*}{$\begin{array}{l}\text { Temperature } \\
\text { (K) }\end{array}$} & \multicolumn{2}{|c|}{$\begin{array}{c}\text { Copper Sulphate } \\
\text { in } 2 \%(w / w) \text { propylene } \\
\text { glycol +water }\end{array}$} & \multicolumn{2}{|c|}{$\begin{array}{l}\text { Zinc Sulphate } \\
2 \%(w / w) \text { propylene } \\
\text { glycol +water }\end{array}$} \\
\hline & $\left(\mathrm{cm}^{3} \mathrm{~mol}^{-1}\right)$ & $\left(\mathrm{cm}^{3} \mathrm{dm}^{3 / 2} \mathrm{~mol}^{-3 / 2}\right)$ & $\left(\mathrm{cm}^{3} \mathrm{~mol}^{-1}\right)$ & $\left(\mathrm{cm}^{3} \mathrm{dm}^{3 / 2} \mathrm{~mol}^{-3 / 2}\right)$ \\
\hline 303.15 & 148.5 & 5.35 & 132.6 & 4.95 \\
\hline 308.15 & 144.2 & 6.26 & 130.3 & 6.20 \\
\hline 313.15 & 144.1 & 6.28 & 129.2 & 7.46 \\
\hline 318.15 & 143.7 & 6.38 & 128.5 & 8.07 \\
\hline
\end{tabular}


with the increase in the amount of propylene glycol in water, which shows that these interactions are strengthened and results in decrease in solvation. Also from Table 1, it is clear that the $\phi_{\mathrm{v}}{ }^{0}$ values are positive and decrease in magnitude in all the compositions of propylene glycol+ water at $308.15 \mathrm{~K}$ for both the transition metals sulphates. The $\phi_{v}{ }^{0}$ values, for both the transition metal sulphates decrease with the increase of propylene glycol content in water which shows that ion- solvent interactions decrease on the addition of propylene glycol in water. So we conclude that propylene glycol solvent has more affinity for water than the ions. Also, on comparing the magnitudes of $\phi_{v}{ }^{0}$ values with the values of $S^{*}{ }_{v}, \phi_{v}{ }^{0}$, values are more in magnitudes than that of $S^{*}$ of the same transition metal sulphates. This concludes that ion-solvent interactions dominate over the ion-ion interactions in water + propylene glycol mixture at $308.15 \mathrm{~K}$.

The volume of transfer $\left(\Delta \bar{V}_{(t)}^{0}\right)$ has also been calculated by using the relation:

$$
\Delta \overline{\mathrm{V}}_{(\mathrm{tr})}^{0}=\Delta_{\mathrm{v}(\mathrm{MS})}^{0}-{ }_{\mathrm{v}(\mathrm{W})}^{0}
$$

Here ${ }_{\mathrm{V} \text { (MS) }}^{0}$ and ${ }_{\mathrm{V}(\mathrm{W})}^{0}$ are the partial molar volumes of transition metal sulphates in mixture of Propylene glycol + water and water as solvents respectively. The values of volume of transfer of transition metal sulphates were recorded in table 1.It is clear from table 1 that $\Delta \overline{\mathrm{V}}_{(\mathrm{tr})}^{\circ}$ values continuously decrease in magnitude with the increase in the content of propylene glycol in water.

The decrease in ${ }_{\mathrm{v}}^{0}$ and $\Delta \overline{\mathrm{V}}_{(\mathrm{tr})}^{0}$ may be trait to the increase in electrostriction in the presence of propylene glycol. The electrostriction effect, which leads to the contraction in the volume of the solvent, is increased in the mixed solvents as compared with that in pure water. This electrostriction effect, again confirming the earlier conclusion of greater affinity of propylene glycol for water. $\Delta \bar{V}_{(t r)}^{2}$ values, for each transition metal sulphates decrease with the increase of propylene glycol amount in water; which may be trait to the increase in solvent - solvent interactions between propylene glycol + water. Since sulphate ion is common in both the salts so from the values of $\Delta \bar{V}_{(t r)}^{0}$ values it is concluded that electrostriction of zinc ion is more than copper ion and hence copper ion is preferentially solvated as compared to zinc ion.

\section{Effect of temperature}

Since the behaviour of the both the electrolytes was found to be linear and same in different composition of propylene glycol + water at $308.15 \mathrm{~K}$, so only one composition system $(2 \% \mathrm{w} /$ w) has been selected for studying the effect of temperature. The experimentally determined values for the five different concentrations of both the transition metal sulphates at four equidistant temperatures $(303.15-318.15 \mathrm{~K})$ have been used to calculate the partial molar volume $\phi^{0}{ }_{v}$ of the salts. The plot of apparent molar volume $\phi_{v}$ against

Table 3: Variation of limiting apparent molar volume expansibilities

$\left(\phi_{\mathrm{E}}^{0}\right)$ for copper sulphate and zinc sulphate in water and $2 \%(w / w)$ propylene glycol + water mixture at different temperatures

\begin{tabular}{|c|c|c|}
\hline Temperature $(\mathrm{K})$ & Copper Sulphate in water & Zinc sulphate in water \\
\hline 303.15 & -3.49 & -1.45 \\
\hline 308.15 & -2.09 & -1.27 \\
\hline 313.15 & -0.70 & -1.09 \\
\hline 318.15 & 0.69 & -0.89 \\
\hline Temperature & $\begin{array}{l}\text { Copper Sulphate in } 2 \%(w / w) \\
\text { propylene glycol + water }\end{array}$ & $\begin{array}{l}\text { Zinc sulphate in } 2 \%(\mathrm{w} / \mathrm{w}) \\
\text { propylene glycol + water }\end{array}$ \\
\hline (K) & $\phi_{E}^{0}\left(\mathrm{~cm}^{3} \mathrm{~mol}^{-1} \mathrm{~K}^{-1}\right)$ & $\phi_{E}^{0}\left(\mathrm{~cm}^{3} \mathrm{~mol}^{-1} \mathrm{~K}^{-1}\right)$ \\
\hline 303.15 & -1.05 & -0.49 \\
\hline 308.15 & -0.66 & -0.33 \\
\hline 313.15 & -0.27 & -0.17 \\
\hline 318.15 & 0.11 & 0.01 \\
\hline
\end{tabular}




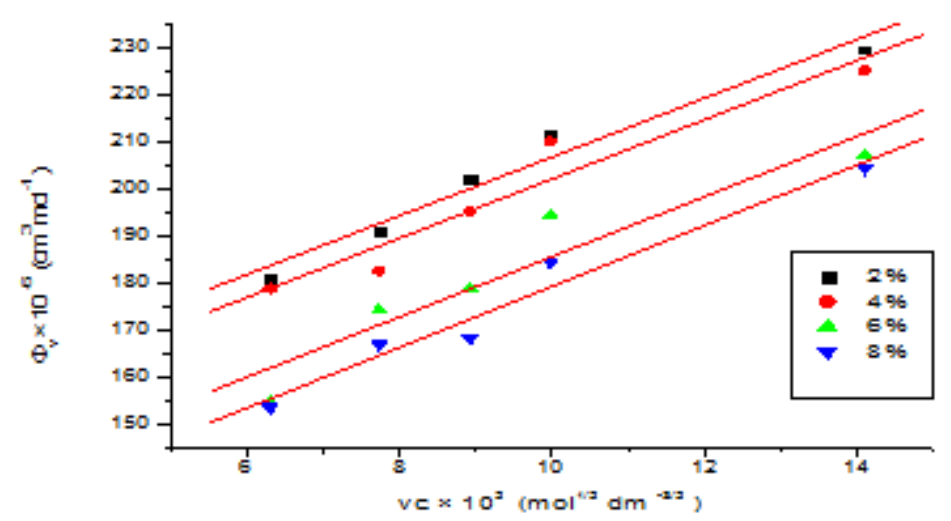

Fig. 1: Plot of $\phi_{\mathrm{v}} \mathrm{Vs} \mathrm{C}^{1 / 2}$ of copper sulphate in different compositions of propylene glycol + water at $308.15 \mathrm{~K}$

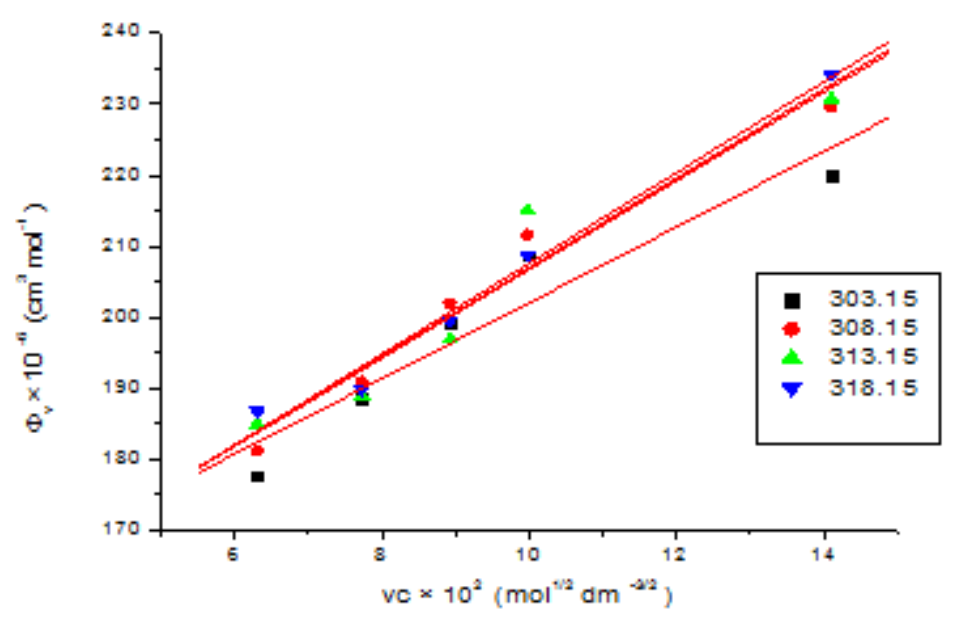

Fig. 2: Plot of $\phi_{\mathrm{v}} \mathrm{Vs} \mathrm{C}^{1 / 2}$ for copper sulphate in $2 \%$ binary mixture of propylene glycol + water at different temperatures

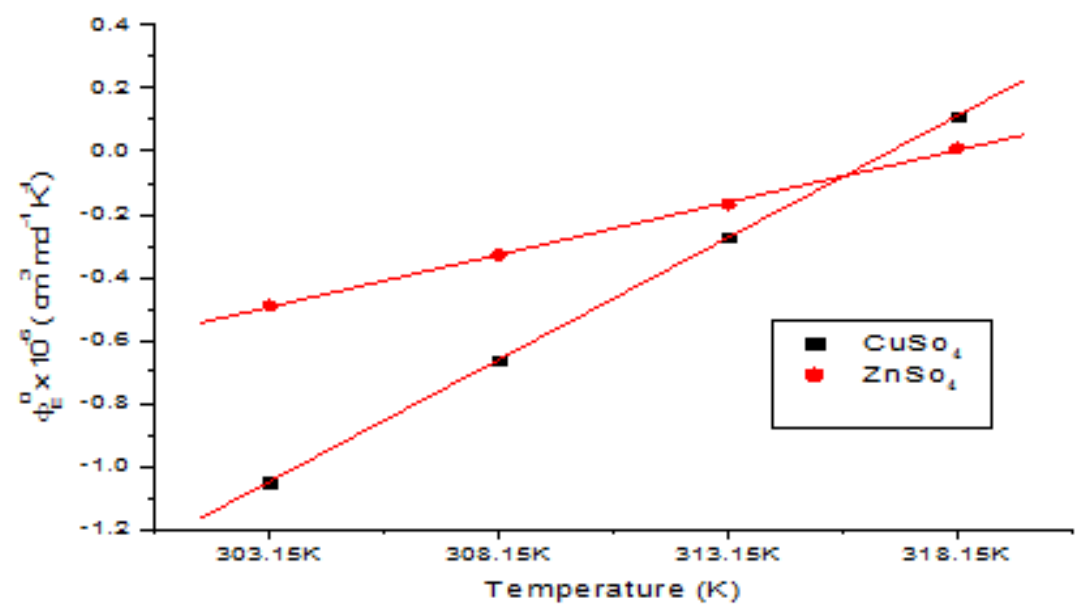

Fig.3: Plot of $\phi_{E}^{0}$ vs temperature for copper sulphate, zinc sulphate in $2 \%$ propylene glycol + water 
the $\sqrt{ } \mathrm{C}$ were found to be linear with the positive slopes in water as well as in binary aqueous solutions of propylene glycol as shown in fig. 2 for copper sulphate as sample plot.

It is evident from table 2 that the values of $\mathrm{S}^{*}$ are positive for both the transition metal sulphates in water and in $2 \%(\mathrm{w} / \mathrm{w})$ propylene glycol+ water at all temperatures. The positive $S^{*}{ }_{v}$ values of transition metal sulphates indicate the presence of strong ion-ion interactions and these values further increase with the increase in temperature. Increase in ion-ion interactions attributes the decrease in the solvation of transition metal ions with rise in temperature. Also it is clear from table 2 , that the values of $\phi_{v}^{0}$ decrease with increase in temperature for both the transition metal sulphates in water and in $2 \%(\mathrm{w} / \mathrm{w})$ propylene glycol + water, thereby showing that ion - solvent interactions are weakened with increase in temperature. The decrease in $\phi_{v}^{0}$ values may be trait to decrease in solvation of transition metal sulphates with rise in temperature.

It has been found that only $S^{*}$ is not only one parameter for determining the structure making or structure breaking nature of any solute. Limiting molar expansibilities $\phi_{\mathrm{E}}^{0}$ is another parameter, which determines the structure making or breaking capacity of any solute in any of the solvent developed by Hepler ${ }^{15}$.

The temperature dependence of $\phi_{v}^{0}$ in water [relations (6) and (7)] and $2 \%$ propylene glycol + water [relations (8) and (9)] for copper sulphate and zinc sulphate can be expressed by the following relations:

${ }_{v}^{0}=13696.71-87.37 \mathrm{~T}+0.1384 \mathrm{~T}^{2}$ for copper sulphate

${ }_{\mathrm{v}}^{0}=3775.67-12.67 \mathrm{~T}+0.0185 \mathrm{~T}^{2}$ for zinc sulphate

$0=4052.2-24.7 \mathrm{~T}+0.039 \mathrm{~T}^{2}$ for copper sulphate $\stackrel{0}{v}=1766.4-10.2 T+0.016 T^{2}$ for zinc sulphate

Limiting molar expansibilities $\phi_{\bar{E}}^{0}=\left[\frac{\partial_{\underline{V}}^{0}}{\partial T}\right] \mathrm{p}$, which is temperature dependence function of ,is calculated for both the transition metal sulphates by using relations (6) to (9) and are given in table 3 .

From table 3, $\phi_{\mathrm{E}}^{0}$ values for transition metal sulphates at different temperatures are negative but increase in magnitude with rise in temperature showing that both these transition metal sulphates behaving just like symmetrical tetra alkyl ammonium salts ${ }^{16}$ and not like common salts ${ }^{17,18}$ because in the case of common electrolytes the molar volume expansibilities should decrease with the rise in temperature. The variation of $\phi_{\mathrm{E}}^{0}$ with temperature, for both the transition metal sulphates is linear and as shown in fig. 3.

This increase in $\phi_{\mathrm{E}}^{0}$ with temperature may be ascribed to the presence of "caging/packing effect". It is also observed from relations (6) to (9) that $\left[\partial^{2}{ }_{v} / \partial T^{2}\right]_{p}$ for the solutions of transition metal sulphates, respectively is positive showing thereby that both the transition metal sulphates behave as structure makers in water and propylene glycol + water mixtures. Hepler has developed a technique of examining the sign of $\left[\partial^{20}{ }_{v} / \partial T^{2}\right]_{p}$ i.e. second derivative of partial molar volume with respect to temperature at constant pressure, for various solutes in terms of long range structure making and breaking capacity of the solutes in aqueous solutions using the general thermodynamic expression [15]:

$$
\left[\partial \mathrm{C}_{\mathrm{P}} / \partial \mathrm{P}\right]_{\mathrm{T}}=-\left[\partial^{2}{ }_{\mathrm{v}} \mathrm{O} / \partial \mathrm{T}^{2}\right]_{\mathrm{p}}
$$

On the basis of this expression, it has been deduced that both the salts are structure makers in water as well as in binary aqueous mixtures of propylene glycol. 


\section{REFERENCES}

1. Parmar M L,;Banyal D S, Indian J Chem, 2005, 44A.

2. Parmar M L,;Guleria M K,; J Indian ChemSoc, 2005, 82.

3. Parmar M L,; Thakur R C,; Proc. Nat. Acad. Sci. India., 2006; 76.

4. Parmar M L,; Thakur R C,; J Mol Liq., 2006, 128.

5. Parmar M L,, Attri S C, J MolLiq, 2007, 136.

6. Oswal S L,;ijardar S P, J MolLiq, 144 (2009).

7. Bhattarai and A,: Das B, J. Nepal Chemistry, 2009, 23.

8. Roy M N.; SahR S.; PradhanP P.; Roy P K.; Russian J. Phy. Chem.A, 2013, 87.

9. Deosarkar S D.; KalyankarT M.; Russian J. Phy. Chem.A, 2013; 87.

10. Thakur R C.; Sonika.; Research J. Pharma, Bio. andChem Sci. 2014, 5 .

11. Shoemaker D.P, Garland C.W,; Experiments in Physical Chemistry, Mc Graw Hill, New York, 1967 p.363.

12. Ward G K,; Millero F J, J Solution Chem, 1974, 3.

13. Weissberger A,; Proskauer E S,; "Techniques of organic chemistry" (Inter Science Publications, New York),1967, VII .

14. Millero F J,; Structure and Transport Processes in water and Aqueous Solution, edited by R A Horne, (Wiley - inter Science, New York) 1971, chap. 13, p 521.

15. Hepler L G, Can J Chem, 1969, 47.

16. Millero $F \mathrm{~J}$, in structure and Transport Processes in water and Aqueous Solution, edited by R A Horne, (Wiley - Inter Science, New York) 1971, chap.15, p 622.

17. Millero,F.J.; Drost Hansen, WJ.P phy. Chem. 1968, 72.

18. Millero F.J, Chem.Rev.1971, 71. 